\title{
Herpes: Issues Under the Cold Sore
}

\author{
Shavitri Mahendiran ${ }^{1}$, Craig G. Burkhart, ${ }^{*}, 1$ and Craig N. Burkhart ${ }^{2}$ \\ ${ }^{1}$ University of Toledo College of Medicine, Sylvania, $\mathrm{OH}$, USA \\ ${ }^{2}$ University of North Carolina at Chapel Hill, Chapel Hill, NC, USA
}

\begin{abstract}
Herpes simplex virus is a widespread disease affecting about one-third of the world's population. Many individuals suffer from its painful and debilitating manifestations, which greatly impact daily living and can lower one's self-esteem and confidence. It is therefore vital to understand this disease process including its acquisition, replication, transmission, clinical manifestations, diagnosis, and treatment in order to better manage patients. While herpes can have many negative consequences, it also appears to offer some benefit to humans through a symbiotic relationship. In this review of herpes, there are three important points that need to be emphasized. First, herpes can be found in all organs throughout the human body and not just the dorsal root ganglion. Secondly, herpes has been proven to be recurrent by laboratory testing. Thirdly, hospitals should institute respiratory (not merely skin) precautions for herpes zoster due to potential airborne transmission.
\end{abstract}

Keywords: Herpes simplex, herpes zoster, airborne transmission, bimodal temporal distribution, herpes reactivation, polymerase chain reaction, recurrent herpes zoster, genetically engineered herpes.

\section{INTRODUCTION}

The scholars of Greek civilization defined herpes which means "to creep or crawl" due to the spreading nature of the lesions. Herpes is a member of the family Herpesviridae which consists of enveloped double-stranded DNA viruses. The Herpesviridae family is divided into three major groups according to biological and genomic behavior including alpha-herpesviruses, beta-herpesviruses, and gammaherpesviruses. The alpha herpesviruses encompass three major viruses which include herpesvirus 1 (HSV-1), herpesvirus 2 (HSV-2), and varicella-zoster virus (VZV). Man serves as the sole natural host to these viruses. HSV-1 and HSV-2 are the most closely related out of all the herpesviruses with $60 \%$ genomic homology.

Herpes is a double stranded DNA virus core surrounded by a capsid that is 100 to $110 \mathrm{~nm}$ in diameter. Surrounding this capsid and tegument is a lipid bilayer envelope consisting of polyamines, lipids and glycoproteins. The glycoproteins contribute to the characteristic properties of the virus. In particular, glycoprotein $\mathrm{G}$ gives antigen specificity to HSV which allows one to differentiate between HSV-1 (gG-1) and HSV-2 (gG-2).

There are many steps involved in the replication of HSV. The DNA is first uncoated and transported to the host cell's nucleus. In the nucleus, the immediate-early genes, which encode for regulatory proteins, are transcribed. Translation subsequently takes place to produce enzymes that are crucial for viral replication and structural proteins. The viral core and capsid are assembled in the nucleus, enveloped at the endoplasmic reticulum and Golgi apparatus. Glycosylation

*Address correspondence to this author at the University of Toledo College of Medicine, 5600 Monroe Street, Suite 106B, Sylvania, OH 43560, USA; Tel: 419-885-3403; Fax: 419-885-3401; E-mail: cgbakb@aol.com takes place in the golgi apparatus and the mature virions are released from the cell via vesicles, which results in cell death.

HSV infections can be found worldwide with one-third of the world's population suffering from recurrent HSV infections. Transmission of HSV requires intimate contact between an individual who is shedding the virus and the host. Once the virus enters the skin or mucous membranes, it replicates within the epithelial cells with an incubation period of four to six days. Cell lysis and inflammation occur as replication continues resulting in the formation of vesicles on an erythematous base. The draining of the infected secretions can also affect the regional lymphatics and the lymph nodes possibly leading to viremia. The virus may ascend the peripheral sensory nerves to reach the dorsal root ganglia. HSV replicates within the neural tissue and then spreads via the peripheral sensory nerves to other mucosal and skin surfaces. HSV-2 infections are more commonly acquired through sexual contact and thus antibodies to the virus are usually not seen until the onset of sexual activity. During gestation, recurrent HSV-2 infections are common which is transmitted as a result of shedding of the virus during delivery [1].

All herpesviruses are able to exist as a latent infection for different amounts of time and then can be reactivated. The latent viral genome can be either extrachromosomal or integrated into the host cell DNA depending on the virus. HSV travels to the dorsal root ganglia by retrograde transmission along sensory nerve pathways. Reactivation can be triggered by a variety of stimuli including stress, menstruation, and exposure to ultraviolet light [1]. Reactivation can result in no symptoms or life-threatening disease.

There is a bimodal temporal distribution of herpetic reactivation. As shown in two studies, when the lips of 
individuals with herpes labialis were exposed to experimental ultraviolet radiation, twenty percent of the individuals experienced eruptions within 24 hours while eighty percent of individuals had lesions that did not erupt until 3 to 5 days following exposure to the radiation $[2,3]$. The eruption at day 1 is due to activation of the HSV located within the epidermal cells, whereas the eruption at day 4 is due to the virus ascending from the dorsal root ganglion [4, 5]. This also occurs with herpes genitalis infection in the same percentages [4]. The bimodal temporal distribution of herpes reactivation is supported by the detection of the herpes virus by PCR within the epidermis in vivo and in vitro in the cultured human keratinocytes [6]. Of note, oral antiherpetic medications provide excellent results for herpes outbreaks related to recurrence from the dorsal root ganglia, but patients in which the herpes is initiated from the skin are recalcitrant to this therapy [4].

\section{CLINICAL MANIFESTATIONS}

HSV can result in a variety of clinical manifestations including gingivostomatitis, acute herpetic pharyngotonsillitis, herpes simplex labialis, genital herpes, aseptic meningitis, herpes encephalitis, herpetic keratitis, and other cutaneous manifestations. Gingivostomatitis is usually caused by HSV-1 and commonly affects children between six months and five years of age. Adults can also develop gingivostomatitis but the manifestations are less severe and commonly include posterior pharyngitis. The mode of infection is infected saliva from an adult or a child. The incubation period is approximately three to six days. Symptoms include high-grade fever, sore throat, pharyngeal edema, erythema, anorexia, regional lymphadenopthy, and vesicular and ulcerative lesions on the oral and pharyngeal mucosa. The most notable feature is gingivitis which presents as distinctly swollen, red, and friable gums.

In adults, acute herpetic pharyngotonsillitis occurs more commonly than gingivostomatitis. It is more commonly caused by HSV-1 infections and results in pharyngitis and tonsillitis. Other symptoms include fever, malaise, headache, sore throat, and may cause oral and labial lesions in less than ten percent of patients. The vesicles can rupture producing ulcerative lesions with characteristic grayish exudates on the tonsils and posterior pharynx. These similar symptoms can also occur with HSV-2 infection associated with orogenital contact or simultaneously with genital herpes.

Recurrent HSV-1 infections in the oropharynx are also known as herpes simplex labialis which are more commonly known as cold sores. This is the most common manifestation of recurrent HSV -1 infection. Pain, burning, and tingling typically occurs at the site of infection with the subsequent eruption of erythematous papules which develop into small intraepidermal vesicles that become pustular and finally ulcerate. They usually can be seen on the vermilion border of the lip. In the first 24 hours of the acute phase of the illness, maximum viral shedding takes place but it can continue for five days.

Genital herpes is most commonly caused by HSV-2 but can also be caused by HSV-1. The clinical features of HSV1 and HSV-2 cannot be distinguished but recurrences are common with HSV-2. Primary genital herpes is typically marked by severe systemic and local manifestations. The symptoms of an individual's first episode of secondary HSV2 infection are usually less severe and last for a shorter period of time, whereas the symptoms of primary genital herpes typically are more severe and persist for a longer duration of time. The incubation period of primary genital herpes is three to seven days with predominantly constitutional symptoms in the first three to four days including pain, itching, dysuria, tender inguinal lymphadenopathy, and vaginal and urethral discharge. The symptoms and complications of primary genital herpes are typically more severe in women than men. In women, the herpetic vesicles appear on the external genitalia, labia majora, labia minora, vaginal vestibule, and introitus. The vesicles rupture resulting in painful ulcerations. The cervix is involved in about $70 \%$ to $90 \%$ of patients and is sometimes the only manifestation. Additional symptoms include dysuria, urethritis, and urinary retention. In men, herpetic vesicles appear on the glans penis, the prepuce, the shaft of the penis, and sometimes on the thighs, scrotum, and buttocks. The lesions become pustules and then encrust. Additional symptoms include urethritis accompanied by dysuria and mucoid discharge. In both men and women, the lesions can remain between four and fifteen days until they encrust.

Herpes reactivation is generally more common in HSV-2 infections than HSV-1 infections. Individuals who experienced severe primary genital herpes infections tend to have more recurrences that last longer. Recurrent genital herpes infections are characterized by pain and burning prior to the eruption of vesicles which can last from two hours to two days. Constitutional symptoms are uncommon. The lesions typically heal in about eight to ten days. Urethritis is uncommon.

Aseptic meningitis can occur in about ten percent of people with primary infection. This can occur when the virus leaves the dorsal root ganglion and travels along the posterior nerve root to the meninges and spinal cord [2]. Herpes simplex encephalitis can occur as two different entities. Herpes simplex encephalitis is localized in the temporal and frontal lobes and caused by HSV-1 in adults and children older than three months. However, in neonates, herpes simplex encephalitis does not have localized involvement in the brain but rather a more generalized involvement. It is usually caused by HSV-2 acquired during delivery. Common symptoms of herpes simplex encephalitis include fever, headache, psychiatric symptoms, seizures, vomiting, focal weakness, and memory loss. The diagnosis is confirmed by PCR which identifies HSV in the cerebrospinal fluid (CSF).

Herpes simplex keratitis is most commonly caused by HSV-1 and results in conjunctivitis. Patients may report symptoms including pain, photophobia, blurred vision, tearing, and redness. HSV keratoconjuctivis produces characteristic dendritic ulcers. It is the most common infectious cause of blindness in the United States. Initial treatment involved the application of topical steroids to the affected area.

Sacral radiculomyelitis is another manifestation which results in neuralgias, urinary retention, or constipation. HSV can infect any area of the skin including abraded skin on the fingers also known as herpetic whitlow. Wrestlers are prone 
to develop disseminated cutaneous lesions called herpes gladiatorum due to the physical contact. Herpes can be found in the parenchyma and stratified squamous epithelium of all the organs of the body $[7,8]$. This can be explained by the asymptomatic viremia which occurs with primary and recurrent infections in immunocompetent hosts [9-11]. This asymptomatic viremia occurs with neonatal, genital, and oromucosal herpes, which is supported by studies demonstrating the existence of the virus in all the organs of the body with polymerase chain reaction (PCR) studies [7].

Recurrent herpes zoster infections can occur, although normal dogma doubts its existence. Secondary outbreaks of varicella zoster virus will occur even in normal immunocompetent individuals with mild flu-like symptoms [12]. These recurrences are more common in patients with compromised immune systems [13-16]. Cases of recurrent herpes zoster has been proven immunologically (such as via immunoglobulin $\mathrm{G}$ antibody levels), or by documenting viremia [13-16]. Patients with neurologic recurrence without skin lesions would be properly designated as zoster sine herpete. Some of these cases demonstrate that herpes virus can not only be spread distally from the dorsal root ganglion to the cutaneous surface, but also are able to disseminate from the dorsal root ganglion and spread proximally along the posterior nerve root to the meninges and spinal cord.

\section{DIAGNOSIS}

Isolation of the virus is necessary to make a definitive diagnosis of HSV. The specimen is then inoculated into cell lines and observed for the appearance of characteristic cytopathic effects. Cells can also be scraped from the lesion and prepared on a glass slide to make a presumptive diagnosis of HSV. The presence of intranuclear inclusions and multinucleated giant cells are characteristic of but not diagnostic of HSV infection. DNA amplification is the diagnostic method of choice when assessing cerebrospinal fluid samples for HSV infection [1]. The preferred diagnostic tests for the detection of HSV are serological tests which can detect the viral glycoprotein $G$ that resides in the lipid bilayer of the virus. This helps distinguish HSV-1 (gG1) from HSV-2 (gG2). About sixty-five percent of patients become seropositive in six weeks but twenty percent don't make antibodies for six months [2].

Polymerase chain reaction (PCR) from genital swabs has been considered a suitable diagnostic approach. PCR enables a more sensitive and rapid diagnostic approach for the detection of herpes. In a study, genital swabs were collected from 233 participants with suspected genital herpes. These swabs were tested by both viral culture and real time PCR. HSV was detected in $34 \%$ of the samples by viral culture and $57 \%$ of the samples by PCR. PCR also increased detection in early (less than five days) and late (more than five days) presentations as well as in first-time and recurrent episodes. HSV detection and typing by PCR was achieved in less than four hours making it significantly more rapid compared to the viral culture. These results were reproducible. Thus, PCR provides a more efficient, sensitive, and reproducible method for the detection of HSV from genital swabs [17].

\section{TREATMENT AND PREVENTION}

Antiviral drugs are the mainstay of therapy when treating HSV-1 and HSV-2 infections. Intravenous acyclovir is the treatment of choice for herpes simplex encephalitis, neonatal HSV infections, and mucocutaneous HSV infections in immunocompromised individuals. Intravenous acyclovir is also used to treat severe initial genital herpes in immunocompetent individuals including those with urinary retention and aseptic meningitis. Valacyclovir and famcyclovir have better pharmokinetics than acyclovir and thus are used to treat non-life-threatening HSV infections. Oral acyclovir, valacyclovir, or famicyclovir can be used to treat non-life-threatening mucocutaneous HSV infections in immunocompromised individuals [18].

Zostavax is the live attenuated zoster vaccine which is an effective and well-tolerated method of preventing zoster and the potentially debilitating sequelae and is recommended for individuals 60 years of age and older $[19,20]$. It is a onedose vaccine that boosts varicella-zoster-specific cell mediated immunity. The cost-effectiveness estimates in pharmacoeconomic analyses vary with country and age group. Concerns about the vaccine include costs of administration, overall health-care costs to society, and acceptance and implementation of the vaccine in the elderly [21].

\section{AIRBORNE TRANSMISSION}

Hospital precautions for herpes should include respiratory precautions because aerosol transmission of herpes occurs. This is supported by studies that were conducted in which PCR was used to detect varicella-zoster virus from the patients' hands, throat and room environment [22-25]. On day four, VZV DNA is found on patient's hands, back of the chairs, doorknobs, and tables in the room. On day 6, VZV DNA was found in the patients' throats and air conditioner filters in the room. The finding that the VZV DNA was detected on the air conditioner is vital because there was no contact between the patient and the air conditioner filter. The biphasic viremia during incubation period of varicella and airborne spread of varicella-zoster virus were shown by virus isolation or by detection of the virus DNA [26]. The airborne transmission of VZV has been documented in several reports. In a long-term care facility, a small outbreak of varicella occurred after one of the nursing home residents developed herpes zoster. Clinical specimens were collected from three patients with varicella and viral analysis showed a unique genotype strain present in all three patients. Widespread contamination was demonstrated by environmental sampling for VZV DNA. Airborne transmission was suspected because VZV easily desiccates which enhances its aerosol transmission [27].

This supports that aerosol transmission of VZV occurs and that special airborne transmission precautions for patients with varicella need to be taken into account to reduce transmission among individuals [26].

\section{BENEFITS OF HERPES - POSSIBLE TREATMENT FOR CANCER}

While herpes infections can cause detrimental effects in many patients, they may bestow some benefits by existing with humans in what can be described as a symbiotic 
relationship. Herpes has been shown to selectively damage cancer cells as well to trigger an immunological response against the cancer. Herpes viruses can be genetically engineered to not replicate in normal tissue and thus can be used to treat certain types of cancer [27]. HSV can be genetically altered such that the gene within the virus is inactivated rendering it incapable of causing systemic infection. The virus is then inserted into a cancer cell. The modified HSV continues to replicated thus causing the cancer cell to burst. A study was completed in which genetically altered HSV was given to patients with melanoma. Five patients with advanced melanoma were given either one, two, or four injections of modified HSV directly into the cancer site prior to removal. All five patients had evidence of prior infection with HSV before receiving the treatment. Areas of cell death could be seen at all injected sites. This vital finding points out that all the patients had an immune response to the injection despite the fact that they all had HSV. The patient who received four injections experienced a decrease in the size of his cancer before it was removed. All patients in the study tolerated their treatments well [28].

\section{CONCLUSIONS}

Herpes simplex virus causes painful and debilitating clinical symptoms for millions around the world. Not only can it impact an individual's health and way of life, but it can also have detrimental psychological consequences. It is therefore crucial to elucidate this disease process and build upon the current knowledge that exists in order to offer better management and treatment options to those living with this condition.

\section{REFERENCES}

[1] Burkhart CG, Burkhart CN. Focus on: Herpes acquisition and transmission. J Drugs Dermatol 2005; 5: 378-84.

[2] Spruance SL, Freeman DJ, Stewart JC. The natural history of ultraviolet radiation-induced herpes simplex labialis and response to therapy with peroral and topical formulations of acyclovir. J Infect Dis 1991; 163: 728-34.

[3] Spruance SL, Kriesel JD, Evans TG, McKeough MB. Susceptibility to herpes labialis following multiple experimental exposures to ultraviolet radiation. Antiviral Res 1995; 28: 57-67.

[4] Burkhart CN, Burkhart CG. The bimodal temporal distribution of herpetic reactivation. Mayo Clinic Proceed 2005; 80: 287-8.

[5] Maratou E, Theophilidis G, Arsenakis M. Axonal transport of herpes simplex virus-1 in an in vitro model based on the isolated sciatic nerve of the frog Rana ridibunda. J Neurosci Methods 1998; 79: $75-8$.

[6] Miura S, Smith CC, Burnett JW, Aurelian L. Detection of viral DNA within skin of healed recurrent herpes simplex infection and erythema multiforme lesions. J Invest Dermatol 1992; 98: 68-72.
[7] Corey L. Herpes simplex viruses. In: Fauci AS, Braunwall E, Isselbacher KJ, Wilson JD, Martin JB, Kasper DL, Hauser SL, Longo DL, eds. Harrison's Principles of Internal Medicine, New York: McGraw-Hill; 1998: pp. 1080-6.

[8] Burkhart CG. Veni, VD, Vici: Twelve concerns with herpetic infections. J Drugs Dermatol 2004; 3: 127-8.

[9] Youssef R, Shaker O, Sobeih S, Mashaly H, Mostafa WZ. Detection of herpes simplex virus DNA in serum and oral secretions during acute recurrent herpes labialis. J Dermatol 2002; 29: 404-10.

[10] Diamond C, Mohan K, Hobson A, Frenkel L, Corey L. Viremia in neonatal herpes virus infections. Ped Inf Dis J 1999; 18: 847-9.

[11] Barinskii KF, Grebeniuk VN, Davydova AA, Malashenko LN Viremia in genital herpes. Vestnik Kermatologii I Venerologii 1982; 1: 16-8.

[12] Donahue JG, Choo PW, Manson JE, et al. The incidence of herpes zoster. Arch Intern Med 1995; 155:1605-9.

[13] Fox RJ, Galetta SL, Mahalingam R, Wellish M, Forghani B, Gilden DH. Acute, chronic, and recurrent varicella zoster virus neuropathy without zoster rash. Neurology 2001; 57: 142-7.

[14] Pena JA, Pirics ML, Julapalli MR, et al. Varicella reactivation presenting as shingles and aseptic meningitis in an immunocompetent 11-7ear-old boy. Clin Pediatr 2009; 48: 435-7.

[15] Sornsen GV, Helgestad J, Roshoj S. Herpes zoster-assocatied morbidity in children undergoing chemotherapy for acute lymphoblastic leukemia. Ugeskr Laeger 2009; 171: 3350-4.

[16] Hu AY, Strauss EC, Holland GN, Chan MF, Yu F, Margolis TP. Late varicella-zoster virus dendriform keratitis in patients with histories of herpes zoster ophthalmicus. Am J Ophthalmol 2010; 149: 214-20.

[17] M Ramaswamy C, McDonald M, Smith D, et al. Diagnosis of genital herpes by real time PCR in routine clinical practice. Sex Transm Infect 2004; 80: 406-10.

[18] Dworkin RH, Johnson RW, Breuer J, et al. Recommendations for the management of herpes zoster. Clin Infect Dis 2007; 44 Suppl 1: S1-26.

[19] Willison CB, Morrison LK, Mendoza N, Tyring SK. Shingles vaccine. Exp Opin Biol Ther 2010; 10: 631-8.

[20] Sanford M, Keating GM. Zoster vaccine (Zostavax): a review of its use preventing herpes zoster and postherpetic neuralgia in older adults. Drugs Aging 2010: 27:159-76.

[21] Liesegang TJ. Varicella zoster virus vaccines: effective, but concerns linger. Can J Opthalmol 2009; 44: 379-84.

[22] Gustafson TL, Lasvely GB, Trawner ER, et al. An outbreak of airborne nosocomial varicella. Pediatrics 1982; 70: 550-6.

[23] Josephson A, Gombert ME. Airborne transmission of nosocomial varicella from localized zoster. J Infect Dis 1988; 158: 238-41.

[24] Sawyer MH, Chamberlin CJ, Wu YN, et al. Detection of varicellazoster virus in air samples from hospital rooms. J Infect Dis 1994; 169: $91-4$

[25] Asano Y. Clinicopathologic understanding and control of varicellazoster virus infection. Vaccine 2008; 26: 6487-90.

[26] Burkhart CN, Barnett R. Herpes zoster; Reassessment of isolation precautions in hospitals. Skin Med 2003; 2: 253-5.

[27] Lopez AS, Burnett-Hartman A, Nambiar R, et al. Transmission of a newly characterized strain of varicella zoster virus from a patient with herpes zoster in a long-term-care facility, West Virginia, 2004. J Infect Dis 2008; 197: 654.

[28] Rona M, Stewart B, Brown S. Intralesional injection of herpes simplex virus 1716 in metastatic melanoma. Lancet 2001; 357: $525-6$.

This is an open access article licensed under the terms of the Creative Commons Attribution Non-Commercial License (http://creativecommons.org/licenses/by-nc/ 3.0/) which permits unrestricted, non-commercial use, distribution and reproduction in any medium, provided the work is properly cited. 